\title{
Comparison of Buoy-Mounted and Bottom-Moored ADCP Performance at Gray's Reef
}

\author{
Harvey E. Seim and Catherine R. Edwards \\ Department of Marine Sciences, University of North Carolina at Chapel Hill, Chapel Hill, North Carolina
}

(Manuscript received 11 January 2005, in final form 10 May 2006)

\begin{abstract}
Simultaneous ADCP profile measurements are compared over a 2-month period in late 2003. One set of measurements comes from a National Data Buoy Center (NDBC) buoy-mounted ADCP, the other from a bottom-mounted, upward-looking ADCP moored roughly $500 \mathrm{~m}$ from the buoy. The study was undertaken to evaluate the proficiency of an experimental configuration by NDBC; unfortunately, the ADCP was not optimally configured. The higher temporally and vertically resolved bottom-mounted ADCP data are interpolated in time and depth to match the buoy-mounted ADCP measurements. It is found that the two ADCP measurements are significantly different. The buoy-mounted measurements are affected by highfrequency $(<10 \mathrm{~h}$ period) noise that is vertically coherent throughout the profiles. This noise results in autospectra that are essentially white, unlike the classic red spectra formed from the bottom-mounted ADCP observations. The spectra imply a practical noise floor of $0.045 \mathrm{~m} \mathrm{~s}^{-1}$ for the buoy-mounted system. Contamination by surface waves is the likely cause of this problem. At tidal frequencies the buoy-mounted system underestimates major axis tidal current magnitude by $10 \%-40 \%$; interference from the buoy chain and/or fish or plankton are considered the most likely cause of the bias. The subtidal velocity field (periods greater than $40 \mathrm{~h}$ ) is only partially captured; the correlation coefficient for the east-west current is 0.49 and for the north-south current is 0.64 .
\end{abstract}

\section{Introduction}

One of the challenges in building an ocean observing system, as called for in a number of studies (Frosch 2000; OCEAN.US 2002; Commission on Ocean Policy 2004), is ensuring accurate real-time observations of ocean circulation. To take advantage of existing platforms there is interest in mounting current profilers on buoys that already have real-time telemetry capabilities. We here explore the effectiveness of a test deployment of a current profiler attached beneath a smaller buoy (3-m diameter) moored on a shallow continental shelf. This analysis complements earlier studies of current profiler capabilities deployed on large (10-m diameter), deep-water buoys by Winant et al. (1994), and similar investigation of using U.S. Coast Guard Aidsto-Navigation (Bosley et al. 2005).

The location for this study is in shallow water $(<20 \mathrm{~m}$

Corresponding author address: Dr. Harvey E. Seim, Department of Marine Sciences, 12-7 Venable Hall, CB 3300, University of North Carolina at Chapel Hill, Chapel Hill, NC 27599.

E-mail: hseim@email.unc.edu deep) on a broad shelf. This is a particularly challenging location for a surface mooring because tidal currents are significant and the wave field is often steep due to shoaling. These factors exert large forces on the surface buoy that affect the catenary of the mooring chain. The combination of the shallow depths and large force on the buoy is likely to prevent the mooring line from hanging vertically over most of the water column, as is often the case in deep-water moorings.

To evaluate the accuracy of current measurements made from the National Data Buoy Center (NDBC) buoy, an upward-looking bottom-mounted ADCP was deployed in close proximity to NDBC buoy 41008 on the Georgia shelf. Assuming that the bottom-mounted system measurements represent "truth," we undertake an evaluation of the buoy-mounted ADCP performance to better understand the validity of these current observations. The assumption that the bottommounted system is accurate is difficult to test except at tidal frequencies, because previous work has clearly delineated the tidal regime (Blanton et al. 2004). We confirm below that the bottom-mounted system accurately reproduces the tidal characteristics at the buoy location

DOI: 10.1175/JTECH1972.1 

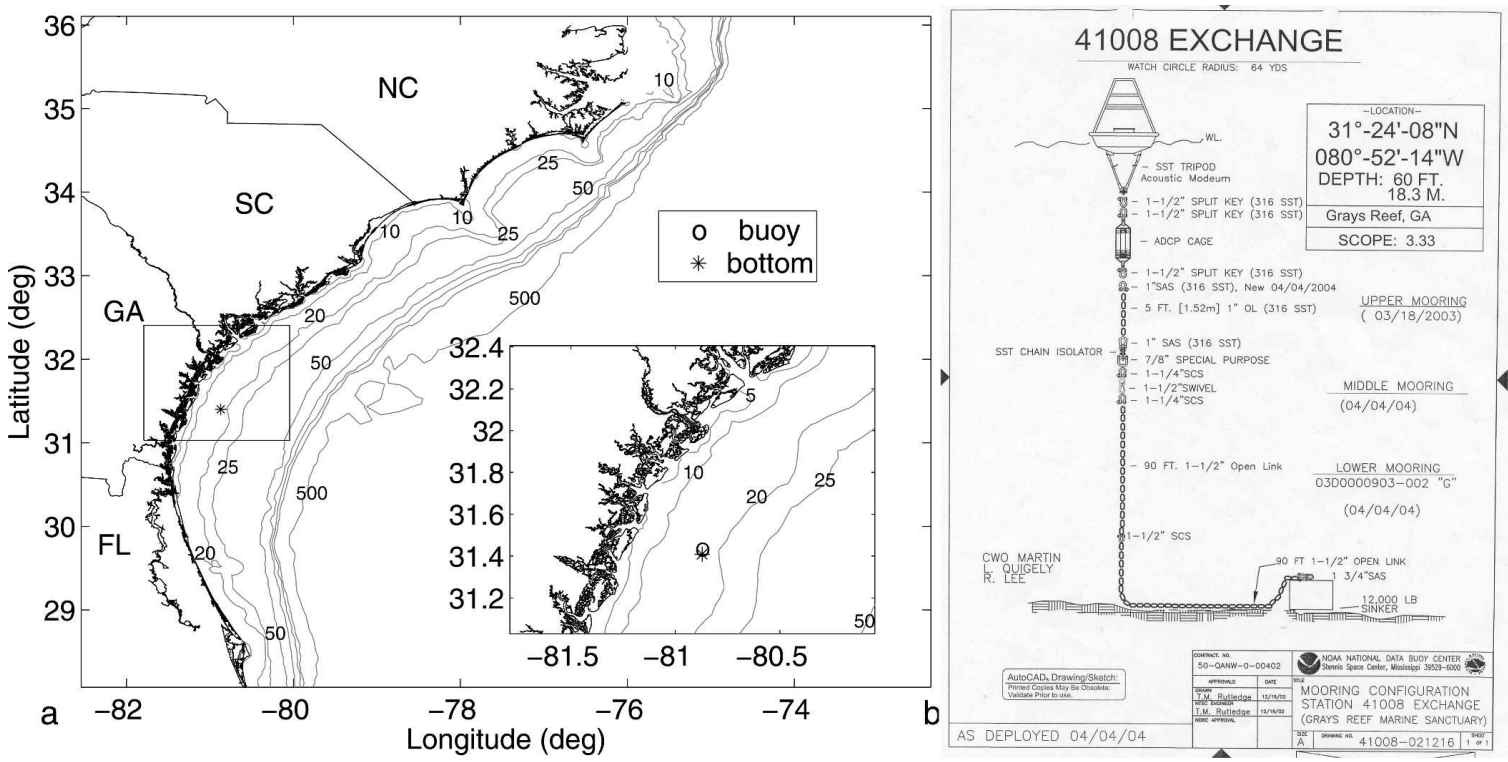

FIG. 1. NDBC buoy 41008 (top) location and (bottom) configuration information. The bottom-mounted location is shown by "bottom."

and take this as at least partial evidence of this system's veracity.

The buoy-mounted ADCP deployment was a first design and, unfortunately, the instrument was not ideally configured for the environment. This study allows us to examine the accuracy of the buoy-mounted ADCP but does not allow us to definitively identify the source of errors. We propose several likely causes and discuss the pros and cons of each. We note that the buoy-mounted system has already been redesigned and further testing is underway.

\section{Data overview}

The instrumentation was deployed at the Gray's Reef National Marine Sanctuary-a large, hardbottomed outcrop $32 \mathrm{~km}$ off the Georgia coastline (Fig. 1). Depths at the site are $15-20 \mathrm{~m}$, which place it on the seaward boundary of the inner shelf according to Lee et al. (1991). The inner shelf is significantly influenced by the coastal frontal zone (CFZ), a nearshore band of brackish water produced through tidal mixing of riverine waters discharged into the South Atlantic Bight (SAB) (Blanton 1981). The following two datasets are compared.

1) In 2003, NDBC buoy 41008 at Gray's Reef National Marine Sanctuary hosted a downward-looking 300$\mathrm{kHz}$ ADCP, housed in a cage beneath the buoy bridle (Fig. 1b). The water depth at this location is nominally $18 \mathrm{~m}$. This buoy-mounted instrument av- eraged data from 120 pings over an hour with 3-m vertical bins to produce hourly vertical profiles of horizontal currents. Table 1 gives more complete configuration information for the bottom- and buoymounted instruments.

The time of the buoy-mounted data was adjusted by $30 \mathrm{~min}$ to reflect the correct time about which the 1-h ensembles are averaged (e.g., a 1300 UTC record is actually averaged about 1230 UTC), and the total depth with respect to the sea surface calculated by adding transducer depth below the sea surface $(2.5 \mathrm{~m})$ to the instrument depth. As is apparent in the tidal analysis below, there appear to be other timing issues consistent with an additional time offset of the buoy-mounted observations. However, we

TABLE 1. Configuration information for the buoy- and bottommounted RDI Workhorse ADCPs, both with $20^{\circ}$ transducer head angle and using wide bandwidth settings.

\begin{tabular}{lcc}
\hline \hline \multicolumn{1}{c}{ Setting } & Buoy mounted & $\begin{array}{c}\text { Bottom } \\
\text { mounted }\end{array}$ \\
\hline Frequency & $300 \mathrm{kHz}$ & $600 \mathrm{kHz}$ \\
Pings per ensemble & 120 & 200 \\
Ensemble averaging period & $60 \mathrm{~min}$ & $30 \mathrm{~min}$ \\
Ensemble standard deviation & $4 \mathrm{~mm} \mathrm{~s}^{-1}$ & $5 \mathrm{~mm} \mathrm{~s}$ \\
Time between ping groups & $30 \mathrm{~s}$ & $9 \mathrm{~s}$ \\
Bin one distance & $5 \mathrm{~m}$ & $2 \mathrm{~m}$ \\
Bin size & $3 \mathrm{~m}$ & $1 \mathrm{~m}$ \\
Pitch/roll corrections & On & Off \\
Enable three-beam solutions & Yes & No \\
\hline
\end{tabular}


have no formal basis to impose further offsets and choose to report the results based on known time corrections. Echo intensity measured by the buoymounted ADCP indicates bottom interference at the lower two bins (centered at 16.5 and $19.5 \mathrm{~m}$ ), consistent with the water depth at this location. The data from these lower two depth bins are discarded for the remainder of this analysis.

2) An upward-looking, bottom-mounted $600-\mathrm{kHz}$ ADCP was deployed approximately $500 \mathrm{~m}$ from the NDBC buoy on 21 October 2003, and was recovered on 20 December 2003. The bottom-mounted ADCP averaged 200 pings over 30 min continuously, at 1-m vertical resolution (Table 1). The depth reference for the bottom-mounted instrument was changed from meters above the bottom to depth from the sea surface to compare the two ADCP records directly. Water depth was defined by the pressure data recorded by the ADCP and was verified using an independent record from a Sea-Bird Electronics Microcat conductivity-temperature-depth sensor collocated with the bottom-mounted ADCP. Depth from the sea surface is then the difference between water depth and height above the bottom and was computed for each ensemble. Outliers were identi- fied as data with four-beam solutions of fewer than $75 \%$ good or with error velocities in excess of 0.1 $\mathrm{m} \mathrm{s}^{-1}$ at any point in space or time and removed (approximately $1.1 \%$ of the in-water dataset). The horizontal velocity record was then interpolated simultaneously to the 1-h temporal and 3-m vertical resolution of the buoy-mounted data using linear triangular elements.

\section{Comparisons}

Figures 2 and 3 display overlays of horizontal velocities and speeds at specific depths and time ranges. General impressions are that both observation systems capture gross trends, but that the buoy-mounted observations are less energetic. This underestimate is most evident at the beginning of the time series and less obvious at the end of the study period. Figure 3 shows 10-day time series of yeardays 300-310 and 340-350, which are taken as representative time series near the beginning and end of the records, respectively. The buoy-mounted ADCP underestimates horizontal velocities at all depths at the beginning of the deployment, but agreement improves significantly by the end of the record. The timing of the shift in data quality occurs near yearday 315 for the velocities from $7.5-\mathrm{m}$ depth

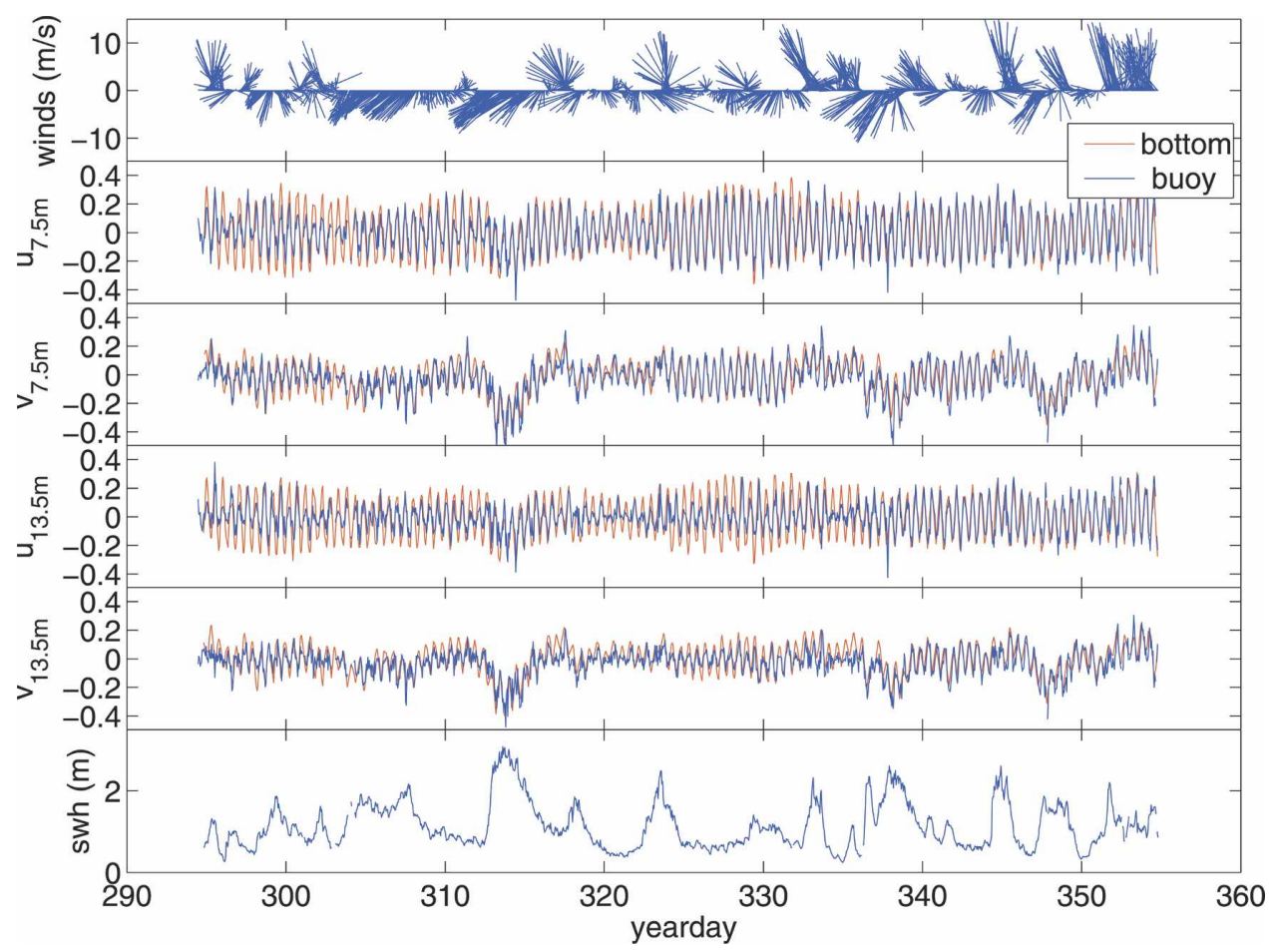

FIG. 2. Middepth and near-bottom zonal $(u)$ and meridional $(v)$ velocities of the bottom-mounted (red) and buoy-mounted (blue) instruments, measured 7.5 and $13.5 \mathrm{~m}$ below the sea surface. Time is given in yeardays and velocity is in meters per second. (top) Wind (direction toward, $\mathrm{m} \mathrm{s}^{-1}$ ) and (bottom) significant wave height $(\mathrm{m})$ are included for reference. 


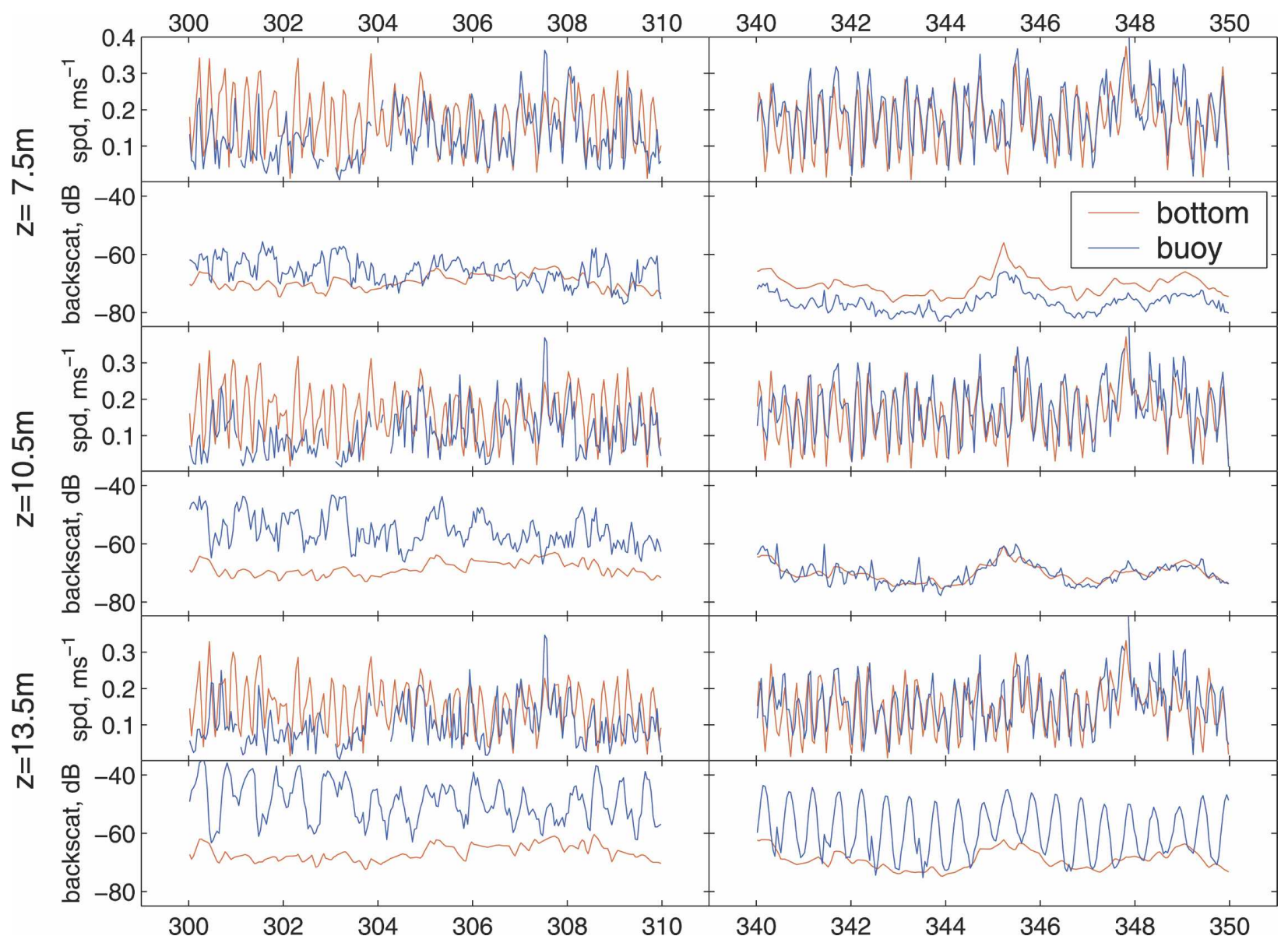

FIG. 3. Ten-day time series from yeardays (left) 300-310 and (right) 340-350 of bottom-based (red) and buoy-mounted (blue) total measured speeds and computed acoustic backscatter at 7.5,10.5, and $13.5 \mathrm{~m}$ below the sea surface. Time is given yeardays, speeds are in meters per second, and backscatter is in decibels.

and near yearday 337 for the lower two depths, and in both cases this shift is associated with strong southwestward winds and enhanced surface waves on the shelf.

Variation in the strength of acoustic backscatter is the only measurement that correlates visually with the shifts in buoy-mounted data quality (Fig. 3). We compare the estimated backscatter from the two ADCPs, but note that the ADCPs operate at different frequencies and that neither unit has been calibrated (i.e., we do not have transmitted or received sensitivities). It appears that both systems sense a similar background level of backscatter, but that the buoy-mounted ADCP sensed elevated backscatter for hours at a time. This difference in backscatter occurred at all depths early on. It persisted throughout the measurement period at 13.5-m depth, but decreased in maximum amplitude and changed in frequency content after yearday 337 , taking on a very tidal character for the last part of the sampling period. The significant current underesti- mates during yeardays 300-304 and 308-310 are seen at all depths and correspond to times of the most elevated backscatter, leading us to speculate that interference by something in the water is the cause. The possible causes of the interference are discussed below.

Figure 4 overlays the vertical component of bottommounted velocity with the buoy-mounted velocities. Vertical velocities reported by the buoy-mounted $\operatorname{ADCP}\left(\leq 0.25 \mathrm{~m} \mathrm{~s}^{-1}\right)$ are unreasonably large compared to those measured by the bottom-mounted instrument. The bursts of large-magnitude vertical velocity show some correspondence with periods of increased instrument pitch-and-roll ensemble means and standard deviations measured by the buoy ADCP (Fig. 5) and to periods of increased significant wave height (Fig. 2) but fall far short of an obvious relationship. Because the buoy-mounted ADCP is not directly connected to the buoy, it is difficult to infer the mooring motions from this record. Rolls are particularly large; hourly mean 


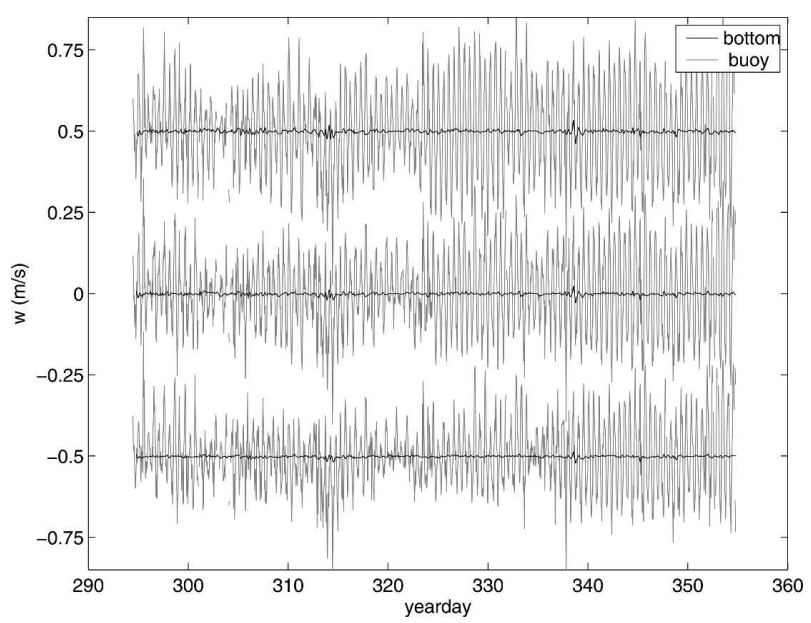

FIG. 4. The 60-day time series of vertical velocity at (top) 7.5, (middle) 10.5, and (bottom) $13.5 \mathrm{~m}$ below the sea surface as measured by the bottom- (black) and buoy-mounted (gray) ADCPs. Each velocity bin is offset by $0.5 \mathrm{~m} \mathrm{~s}^{-1}$ for clarity.

values reach $10^{\circ}$ during strong storms, indicating that a pronounced catenary exists in the mooring chain during these events. Note also that the magnitude of the roll is persistently larger than the pitch, and implies either a specific orientation with respect to either the buoy/ mooring or possibly a malfunctioning sensor. The excessively large buoy-mounted vertical velocities indicate that the pitch-and-roll corrections applied to the beam-coordinate data did not work, likely because of the inability of the pitch/roll sensors to accurately measure the dynamic buoy motion.

Corrections applied with the measured pitch and roll can introduce significant error into the corrected velocities. Appell and Williams (1993) suggest that the time constants associated with the ADCP's internal compass and pitch/roll sensors are inappropriate for accurate operation under dynamic conditions. While the effect of the pitch-and-roll correction transfers some of the variance of the horizontal velocity into the vertical, a comparison of the magnitudes of total velocities (Fig. 6) indicates that the correction explains only some of the differences in the signals, and further analysis is warranted. In particular, the trend of increasing agreement in time between the two systems cannot be explained by surface wave field effects and instead appears to be related to the variations in backscatter strength. To fully quantify the differences between the two datasets, a series of different comparisons have been undertaken-profiles of mean velocities and standard deviations, tidal analysis, spectral analysis, and variance and RMS differences of specific frequency bands. They collectively reveal a series of issues with the buoymounted ADCP measurements.

\section{a. Basic statistics}

Figure 7 shows profiles of time series means and standard deviations of $u$ and $v$ components of velocity measured by the bottom- and buoy-mounted instruments, where they are available. Considering first the mean bottom-based ADCP currents, weak surface-trapped southward flow and weak cross-shelf exchange flow were observed. The near-zero southward bottom speed is consistent with thermal wind shear because of the cross-shelf density gradient of the CFZ (Blanton 1981), as is the cross-shelf estuarine-like exchange flow, previously noted by Blanton (1996). The buoy-mounted system does not measure the upper half of the water column, and cannot observe the degree of shear present in the bottom-based measurements. Mean zonal velocities agree reasonably well where buoy-mounted data are available, but meridional velocity measured by the buoy-mounted ADCP overestimates the southward current, with decreasing agreement toward the seafloor.

This indication of possible signal degradation with depth is also seen in the time series standard deviations. The buoy-mounted ADCP standard deviation measurements show a rapid decrease in magnitude with depth not seen in the bottom-mounted ADCP observations. Standard deviation calculated from the bottom-based ADCP decreases toward the bed in a fashion reminiscent of a logarithmic boundary layer, with the greater variance in the east-west direction largely resulting from the cross-shelf orientation of the tide (Pietrafesa et al. 1985; Blanton et al. 2004). While standard deviation in the east-west buoy-measured velocity is greater than that in the north-south direction, the relative magnitude of the deviations is smaller than for the bottom-mounted instrument.

A scatterplot of the data, shown as bin-averaged distributions of both components of velocity (Fig. 8), reveals a relatively large range of scatter (standard deviations of $0.05-0.08 \mathrm{~m} \mathrm{~s}^{-1}$ ) for the buoy velocities against the bottom-based measurements. A simple linear regression shows no appreciable bias in buoy-measured zonal velocity (zero intercept of $\sim 0.00 \pm 0.001 \mathrm{~m} \mathrm{~s}^{-1}$ ) and a slight negative bias in the meridional velocity (zero intercept of $-0.02 \pm 0.03 \mathrm{~m} \mathrm{~s}^{-1}$ ). The slopes of the scatter in the $u$ and $v$ components of velocity ( 0.66 \pm 0.10 and $0.80 \pm 0.09$, respectively) indicate underprediction of the buoy-mounted system relative to the bottom-mounted instrument, with greater underprediction of the zonal velocities.

Error velocities (a measure of current estimate consistency possible with four-beam systems) are generally random, and the profiles of root-mean-square values 

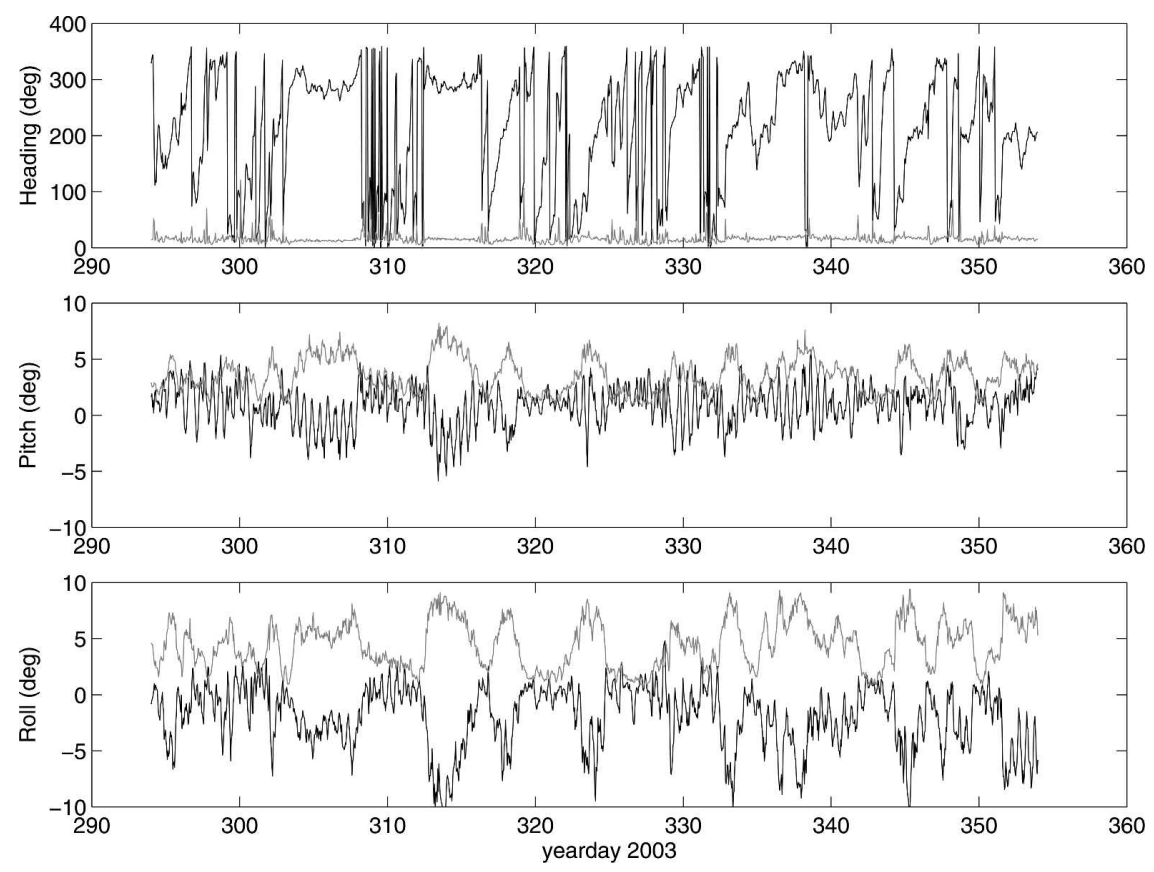

FIG. 5. Heading, pitch, and roll $\left({ }^{\circ}\right)$ measured by the buoy-mounted ADCP. Ensemble averages are shown in black and ensemble standard deviations in gray.

(Fig. 9) largely confirm the manufacturer's estimates of standard deviations (Table 1) for the bottom-mounted ADCP. Buoy-mounted RMS error values are 0.015$0.02 \mathrm{~m} \mathrm{~s}^{-1}$, about 4 times the expected ensemble devia- tion of $0.004 \mathrm{~m} \mathrm{~s}^{-1}$. One other feature is notable-the exponential increase in RMS error velocities in the upper $10 \mathrm{~m}$ of the water column measured from the bottom mount. There is no indication that the increased

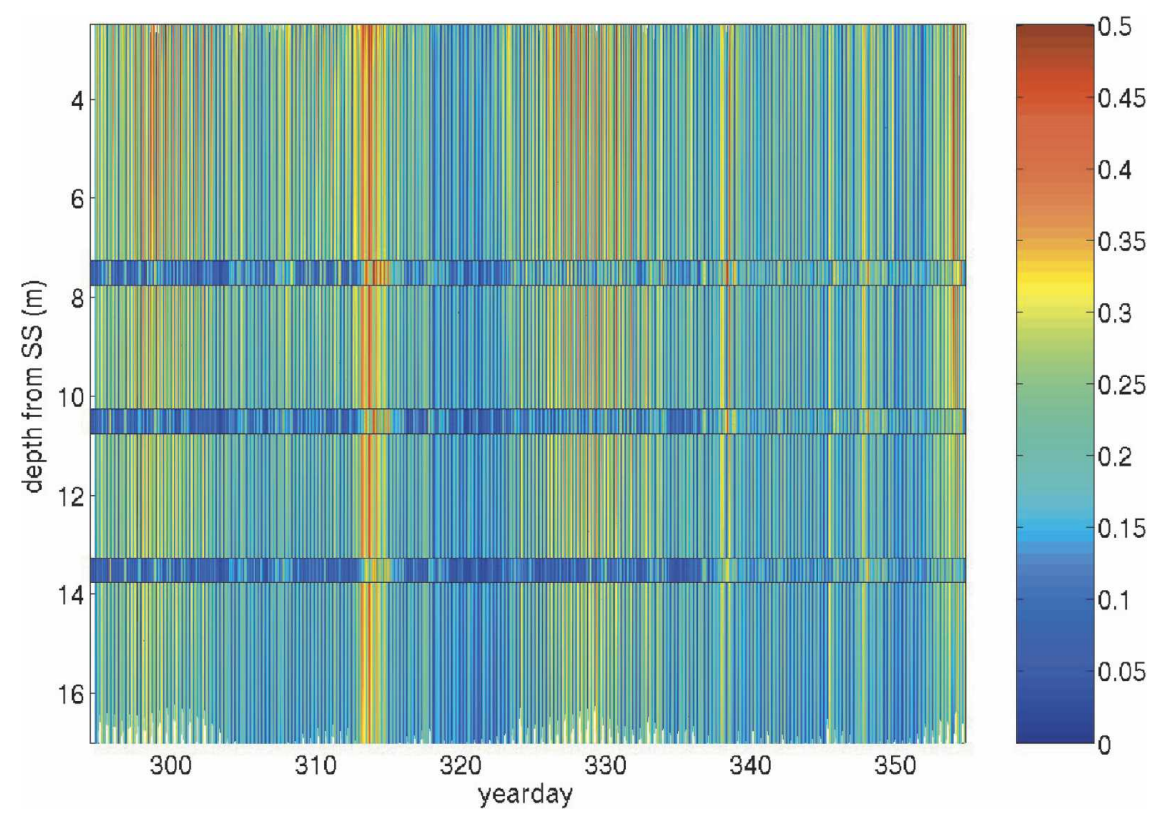

FIG. 6. Magnitude of the total velocities $\left(\mathrm{m} \mathrm{s}^{-1}\right)$ measured by the bottom- (background) and buoy-mounted (overlaid strips) ADCPs over the 60-day deployment. Time is given in yeardays, and depth is in meters. 

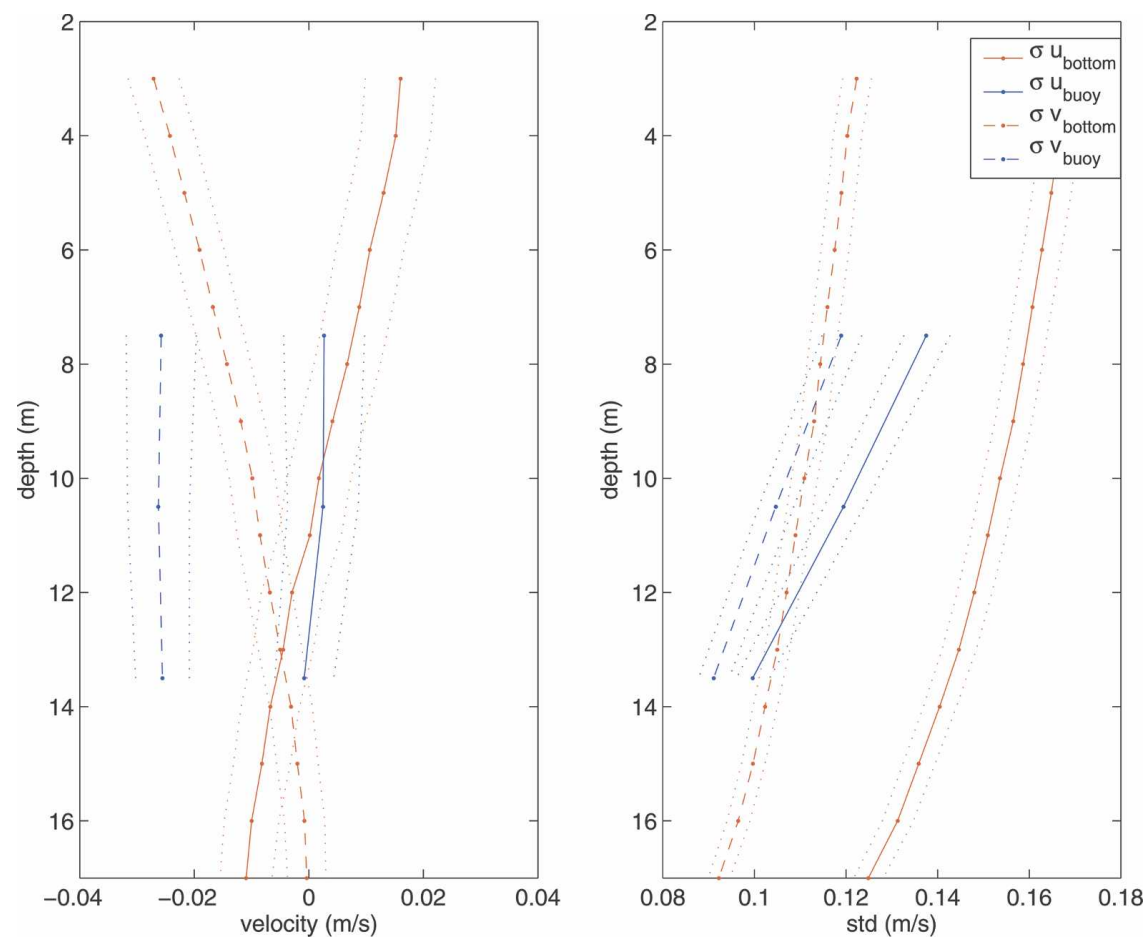

FIG. 7. Time series mean and standard deviations of bottom- (red) and buoy-mounted (blue) zonal $\left(u\right.$, solid) and meridional $\left(v\right.$, dashed) velocities $\left(\mathrm{m} \mathrm{s}^{-1}\right)$. Dashed lines are $95 \%$ confidence intervals around each curve.

error results from signal degradation; we suspect it reflects processes in the upper water column that produce heterogeneity in the velocity field, for example, Langmuir cells (Gargett et al. 2004).

\section{b. Tides}

As previously mentioned, assessment of the observational skill of ADCP measurements presented here is limited to comparison of tidal dynamics. Tides dominate the variance in currents on the shelf, with the $M_{2}$ tide contributing on the order of $80 \%$ of kinetic energy on the inner to midshelf (Pietrafesa et al. 1985); thus, agreement of a thorough tidal analysis with that of previous work in the South Atlantic Bight is a benchmark of instrument fidelity. A shelf-wide, combined observational and modeling study of tides in the South Atlantic Bight (Blanton et al. 2004) is used as the basis for comparison of tidal analyses.

Table 2 shows a portion of the output from least squares fits of the astronomical tide to the bottombased depth-averaged tidal current (Pawlowicz et al. 2002). For brevity, a subset of the tidal constituents with signal-to-noise ratio (SNR) greater than 5 in the bottom-based measurements is listed. Clearly, the principal lunar tide $\left(M_{2}\right)$ dominates the signal (Table 2), with two other semidiurnal constituents $\left(S_{2}\right.$ and $\left.N_{2}\right)$ exceeding $0.02 \mathrm{~m} \mathrm{~s}^{-1}$ magnitude. The $M_{2}$ and $K_{1}$ amplitudes, inclinations, and phases agree with those of Blanton et al. (2004) to within $0.01 \mathrm{~m} \mathrm{~s}^{-1}$ and $3^{\circ}$, giving a good degree of confidence in the accuracy of velocity measured by the bottom-mounted system.

Similar tidal analysis of the buoy-mounted measurements is possible, but depth-averaged buoy-derived currents are an average only over the lower half of the water column, and are not directly comparable to the bottom-based results. The results of tidal analysis of the currents at 7.5, 10.5, and $13.5 \mathrm{~m}$ below the sea surface are summarized in Table 3. Forming the error as (|buoy| - |bottom|)/|bottom|, we find the $M_{2}$ major axis amplitude underestimate to be $-13 \%$ at $7.5-\mathrm{m}$ depth, increasing to $-36 \%$ at $13.5 \mathrm{~m}$. Similar trends are apparent in other tidal constituents and in the semiminor axis amplitudes. The phases of tidal constituents are approximately $15^{\circ}$ later at all depths in buoy-mounted semidiurnal values, suggesting an unexplained 30-min offset. Ellipse inclination differs by $4^{\circ}-5^{\circ}$, consistent at all depths, indicative of a small directional offset. It is apparent that the simple depth and time offsets identified earlier are not the only causes of differences between the two systems. 

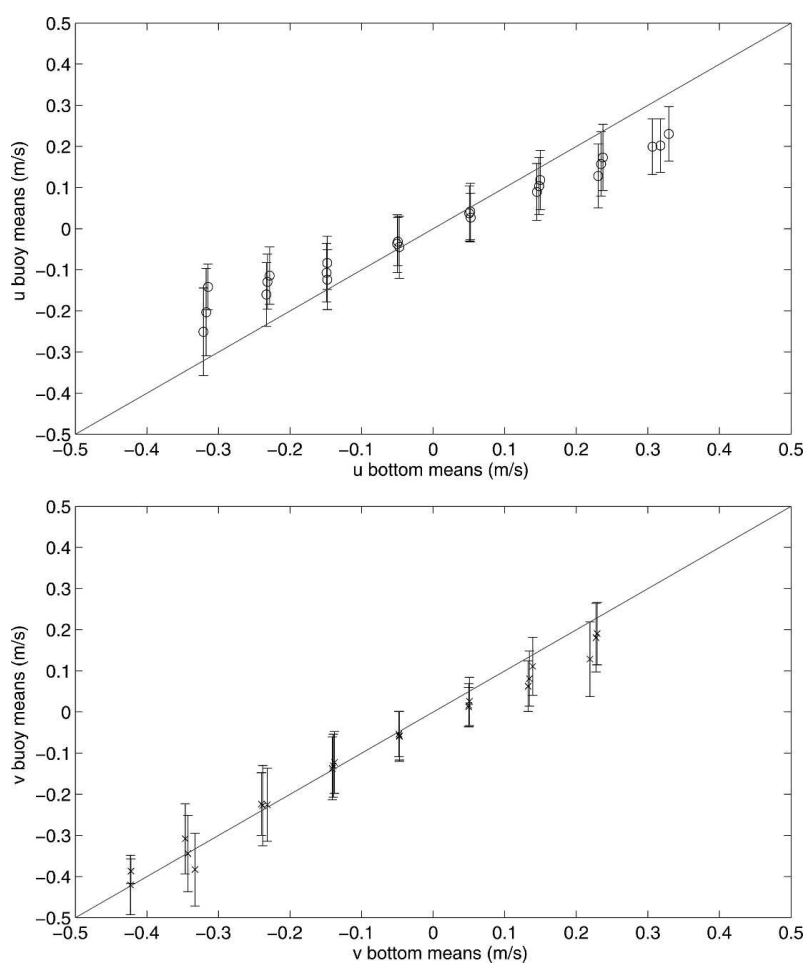

FIG. 8. Bin-averaged distribution of (top) $u$ and (bottom) $v$ components of velocity measured by the bottom- and buoymounted instruments. Mean (symbols) and one standard deviation bounds (vertical lines) were calculated over $0.1 \mathrm{~m} \mathrm{~s}^{-1}$ bins of the bottom-mounted ADCP observations.

Tidal current predictions based on this analysis yield a comparison that fails to correctly capture the general character of the tidal currents (Fig. 10). The predicted tidal currents from the bottom-mounted ADCP at

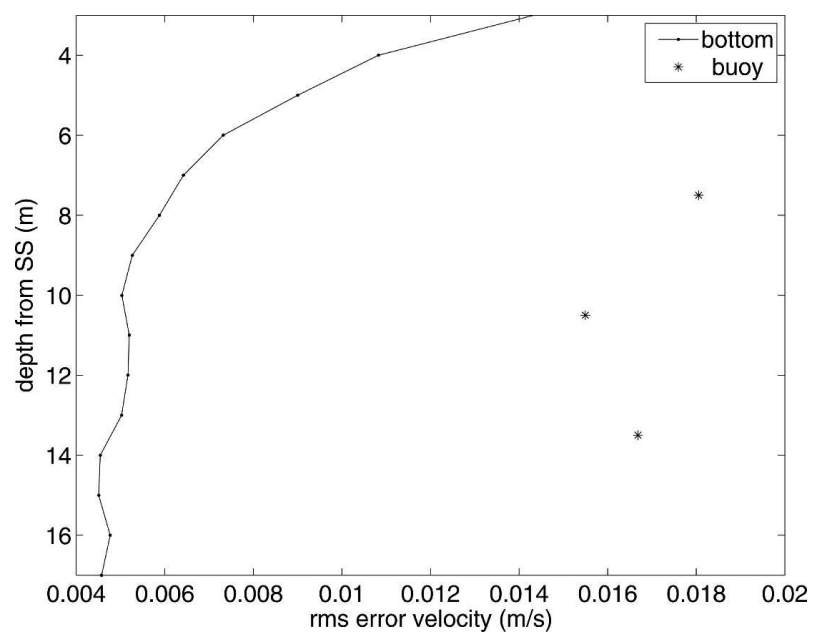

FIG. 9. Root-mean-square error velocity profiles are consistent with expected standard deviations. The cause of the near-surface increase is unclear. 10.5-m depth are seen to exhibit the typical spring-neap cycle of the $\mathrm{SAB}$, with one major spring tide each month. The periods of increased magnitude of tidal variation seen near yeardays 300 and 330 are caused by the prominence of the $\mathrm{N}_{2}$ constituent, which has a 28day beat frequency with the $M_{2}$ tide. This important tidal characteristic is not captured in the tidal prediction from the buoy-mounted ADCP measurements.

Detided $u$ and $v$ components of velocity at $10.5-\mathrm{m}$ depth (Fig. 10) generally track well, though the buoymounted detided velocities exhibit noise of $0.05-0.1$ $\mathrm{m} \mathrm{s}^{-1}$ not seen in the bottom-based velocities. Underestimation of the tides likely accounts for the bulk of the difference in variance seen over the full signal (Fig. 7). The source of the high-frequency variance in the nontidal residual is investigated below.

\section{c. Spectra}

Semidiurnal tides dominate the spectral content of the measured currents (Fig. 11). This is most obvious in the east-west component, which, because it is close to being aligned with the cross-shore direction, displays less energy at subtidal frequencies than the north-south component. Referring to the bottom-mounted ADCP data in Fig. 11, the $u$ spectrum is red, rolling off at approximately $f^{-1.5}$ at frequencies greater than the diurnal tides; the $v$ spectrum is also red but rolls off more steeply, at close to $f^{-2}$, over nearly the entire bandwidth sampled. The $v$ spectrum appears to reach a noise floor at high frequencies, leveling off at about $2 \times 10^{-5}$ $\mathrm{m}^{2} \mathrm{~s}^{-2} \mathrm{cph}^{-1}$. This implies a noise velocity of $v_{n}=$ $\sqrt{P_{\text {noise }} \Delta f}=0.004 \mathrm{~m} \mathrm{~s}^{-1}$ (where $\Delta f$ is $0.5 \mathrm{cph}$ ), similar to that expected from instrument configuration.

Spectra of the buoy-mounted ADCP measurements (Fig. 11) are similar to the bottom-based measurements at low frequencies, but do not exhibit a noticeable roll off in energy with increasing frequency. With the exception of the tides, the spectra are essentially white, a feature indicative of random noise and suggestive of contamination of the signal by some form of environmental noise. The noise floor $P_{\text {noise }}$ for the spectra is $1-2 \times 10^{-3} \mathrm{~m}^{2} \mathrm{~s}^{-2} \mathrm{cph}^{-1}$. This indicates an effective noise velocity of $0.045 \mathrm{~m} \mathrm{~s}^{-1}$. This noise velocity is $0.3-$ 0.45 , the magnitude of the root-mean-square tidal amplitude and roughly $10 \%$ of the maximum currents measured by the buoy-mounted instrument.

To establish how well the tidal prediction captures variance at tidal frequencies, we compare spectra of the raw and detided records (Fig. 11). For the bottommounted system, the spectra of the detided records display no significant peaks at diurnal or semidiurnal frequencies; overtides are less successfully captured. We interpret this as confirmation that the bottom-mounted 
TABLE 2. Results of tidal analysis to the depth-averaged currents from the bottom-mounted ADCP. Semimajor and -minor axes magnitudes are given $\left(\mathrm{mm} \mathrm{s}^{-1}\right)$, and inclination and phase are given $\left(^{\circ}\right)$ for selected constituents.

\begin{tabular}{ccccrr}
\hline \hline Constituent & $\begin{array}{c}\text { Semimajor axis } \\
\left(\mathrm{mm} \mathrm{s}^{-1}\right)\end{array}$ & Semiminor axis $\left(\mathrm{mm} \mathrm{s}^{-1}\right)$ & Inclination $\left(^{\circ}\right)$ & Phase $\left(^{\circ}\right)$ & SNR \\
\hline$O_{1}$ & $11 \pm 4$ & $-8 \pm 5$ & $131.0 \pm 59.6$ & $122.9 \pm 58.6$ & 5.9 \\
$K_{1}$ & $19 \pm 5$ & $-4 \pm 5$ & $134.6 \pm 16.1$ & $106.4 \pm 15.6$ & 13.8 \\
$N_{2}$ & $75 \pm 7$ & $-15 \pm 7$ & $154.4 \pm 5.0$ & $268.6 \pm 4.8$ & 121.3 \\
$M_{2}$ & $250 \pm 6$ & $-58 \pm 7$ & $154.2 \pm 1.6$ & $285.8 \pm 1.5$ & 1579.9 \\
$S_{2}$ & $43 \pm 6$ & $-12 \pm 6$ & $152.6 \pm 9.2$ & $291.3 \pm 10.5$ & 50.2 \\
$M_{4}$ & $11 \pm 2$ & $2 \pm 2$ & $123.2 \pm 12.3$ & $127.6 \pm 11.4$ & 29.8 \\
$M_{4}$ & $7 \pm 2$ & $-2 \pm 2$ & $124.5 \pm 18.5$ & $128.0 \pm 18.7$ & 12.2 \\
\hline
\end{tabular}

system has faithfully recorded the principal tidal signal. The same cannot be said of the buoy-mounted system, because marginally significant energy remains in the detided record at semidiurnal frequencies, likely associated with the underestimation of tidal amplitudes seen in Table 3.
An examination of the velocity component power spectrum as a function of depth reveals several interesting features (Fig. 12). Most obvious is the more rapid fall off of energy at high frequencies near the bottom and in the north-south direction. This is consistent with energy loss to the bottom at supertidal frequencies and

TABLE 3. Results of tidal analysis to buoy-mounted current measurements and interpolated bottom-based currents. Semimajor and -minor axes lengths are given $\left(\mathrm{mm} \mathrm{s}^{-1}\right)$, and inclination (counterclockwise relative to east) and phase (relative to Greenwich) are given $\left(^{\circ}\right)$.

\begin{tabular}{|c|c|c|c|c|c|c|}
\hline \multicolumn{2}{|c|}{$\mathrm{Z}=7.5 \mathrm{~m}$ constituent } & \multirow{2}{*}{$\begin{array}{c}\text { Semimajor axis }\left(\mathrm{mm} \mathrm{s}^{-1}\right) \\
12 \pm 6\end{array}$} & \multirow{2}{*}{$\begin{array}{c}\text { Semiminor axis }\left(\mathrm{mm} \mathrm{s}^{-1}\right) \\
-8 \pm 6\end{array}$} & \multirow{2}{*}{$\begin{array}{c}\text { Inclination }\left(^{\circ}\right) \\
161.0 \pm 57.9\end{array}$} & \multirow{2}{*}{$\begin{array}{l}\text { Phase }\left(^{\circ}\right) \\
83.1 \pm 68.8\end{array}$} & \multirow{2}{*}{$\frac{\mathrm{SNR}}{3.4}$} \\
\hline$O_{1}$ & Bottom & & & & & \\
\hline & Buoy & $9 \pm 7$ & $-5 \pm 7$ & $101.8 \pm 61.5$ & $163.3 \pm 70.7$ & 1.9 \\
\hline \multirow[t]{2}{*}{$K_{1}$} & Bottom & $24 \pm 8$ & $-5 \pm 7$ & $137.8 \pm 20.4$ & $114.9 \pm 19.7$ & 9.8 \\
\hline & Buoy & $22 \pm 7$ & $-3 \pm 8$ & $140.4 \pm 22.8$ & $110.7 \pm 25.4$ & 11 \\
\hline \multirow{2}{*}{$N_{2}$} & Bottom & $60 \pm 6$ & $-13 \pm 7$ & $154.7 \pm 6.9$ & $266.3 \pm 6.8$ & 86.8 \\
\hline & Buoy & $41 \pm 13$ & $-7 \pm 10$ & $148.8 \pm 19.2$ & $287.9 \pm 19.4$ & 10.2 \\
\hline \multirow{2}{*}{$M_{2}$} & Bottom & $217 \pm 7$ & $-37 \pm 7$ & $155.0 \pm 2.0$ & $283.3 \pm 2.1$ & 945.8 \\
\hline & Buoy & $189 \pm 13$ & $-45 \pm 13$ & $150.4 \pm 4.1$ & $301.0 \pm 4.1$ & 208.1 \\
\hline \multirow[t]{2}{*}{$S_{2}$} & Bottom & $36 \pm 8$ & $-12 \pm 6$ & $148.9 \pm 12.7$ & $295.7 \pm 11.9$ & 21.6 \\
\hline & Buoy & $27 \pm 14$ & $-5 \pm 11$ & $148.3 \pm 31.3$ & $306.2 \pm 29.6$ & 3.8 \\
\hline \multicolumn{2}{|c|}{$\mathrm{Z}=10.5 \mathrm{~m}$ constituent } & Semimajor axis $\left(\mathrm{mm} \mathrm{s}^{-1}\right)$ & Semiminor axis $\left(\mathrm{mm} \mathrm{s}^{-1}\right)$ & Inclination $\left(^{\circ}\right)$ & Phase $\left({ }^{\circ}\right)$ & SNR \\
\hline \multirow{2}{*}{$O_{1}$} & Bottom & $11 \pm 5$ & $-7 \pm 5$ & $158.4 \pm 64.0$ & $90.4 \pm 61.9$ & 3.8 \\
\hline & Buoy & $16 \pm 6$ & $-7 \pm 6$ & $143.8 \pm 31.2$ & $112.5 \pm 33.7$ & 8.6 \\
\hline \multirow{2}{*}{$K_{1}$} & Bottom & $21 \pm 7$ & $-6 \pm 7$ & $137.4 \pm 18.5$ & $114.9 \pm 21.0$ & 9.6 \\
\hline & Buoy & $16 \pm 7$ & $-2 \pm 5$ & $139.5 \pm 25.5$ & $95.1 \pm 22.7$ & 5.7 \\
\hline \multirow[t]{2}{*}{$N_{2}$} & Bottom & $57 \pm 6$ & $-12 \pm 6$ & $154.9 \pm 6.9$ & $264.6 \pm 6.4$ & 86.2 \\
\hline & Buoy & $32 \pm 13$ & $-5 \pm 10$ & $149.7 \pm 20.5$ & $290.7 \pm 27.2$ & 5.5 \\
\hline \multirow[t]{2}{*}{$M_{2}$} & Bottom & $207 \pm 7$ & $-33 \pm 6$ & $155.0 \pm 1.8$ & $282.1 \pm 1.9$ & 917.8 \\
\hline & Buoy & $158 \pm 13$ & $-36 \pm 10$ & $150.4 \pm 4.5$ & $300.3 \pm 5.2$ & 139.9 \\
\hline \multirow[t]{2}{*}{$S_{2}$} & Bottom & $34 \pm 6$ & $-10 \pm 5$ & $150.1 \pm 11.3$ & $292.1 \pm 13.2$ & 31.4 \\
\hline & Buoy & $23 \pm 13$ & $-5 \pm 10$ & $148.7 \pm 30.5$ & $311.4 \pm 34.9$ & 2.9 \\
\hline \multicolumn{2}{|c|}{$\mathrm{Z}=13.5 \mathrm{~m}$ constituent } & Semimajor axis $\left(\mathrm{mm} \mathrm{s}^{-1}\right)$ & Semiminor axis $\left(\mathrm{mm} \mathrm{s}^{-1}\right)$ & Inclination $\left(^{\circ}\right)$ & Phase $\left({ }^{\circ}\right)$ & SNR \\
\hline \multirow[t]{2}{*}{$O_{1}$} & Bottom & $10 \pm 6$ & $-5 \pm 4$ & $161.4 \pm 45.2$ & $98.7 \pm 47.7$ & 3.5 \\
\hline & Buoy & $15 \pm 6$ & $-6 \pm 5$ & $145.2 \pm 32.0$ & $114.9 \pm 31.5$ & 6.7 \\
\hline \multirow[t]{2}{*}{$K_{1}$} & Bottom & $20 \pm 6$ & $-6 \pm 5$ & $136.8 \pm 14.5$ & $115.8 \pm 19.8$ & 12.9 \\
\hline & Buoy & $14 \pm 7$ & $-2 \pm 6$ & $138.9 \pm 25.4$ & $88.3 \pm 27.7$ & 4.3 \\
\hline \multirow[t]{2}{*}{$\mathrm{N}_{2}$} & Bottom & $54 \pm 7$ & $-10 \pm 6$ & $155.3 \pm 6.6$ & $262.3 \pm 7.7$ & 67.8 \\
\hline & Buoy & $22 \pm 13$ & $-3 \pm 12$ & $148.9 \pm 35.2$ & $293.7 \pm 39.6$ & 2.6 \\
\hline \multirow{2}{*}{$M_{2}$} & Bottom & $191 \pm 7$ & $-29 \pm 5$ & $154.8 \pm 1.7$ & $281.3 \pm 2.0$ & 829.2 \\
\hline & Buoy & $122 \pm 14$ & $-27 \pm 12$ & $150.6 \pm 5.2$ & $297.8 \pm 7.8$ & 71.6 \\
\hline \multirow[t]{2}{*}{$S_{2}$} & Bottom & $33 \pm 6$ & $-10 \pm 6$ & $151.4 \pm 12.1$ & $290.2 \pm 12.9$ & 32.5 \\
\hline & Buoy & $20 \pm 13$ & $-3 \pm 10$ & $150.5 \pm 38.2$ & $308.9 \pm 44.4$ & 2.3 \\
\hline
\end{tabular}



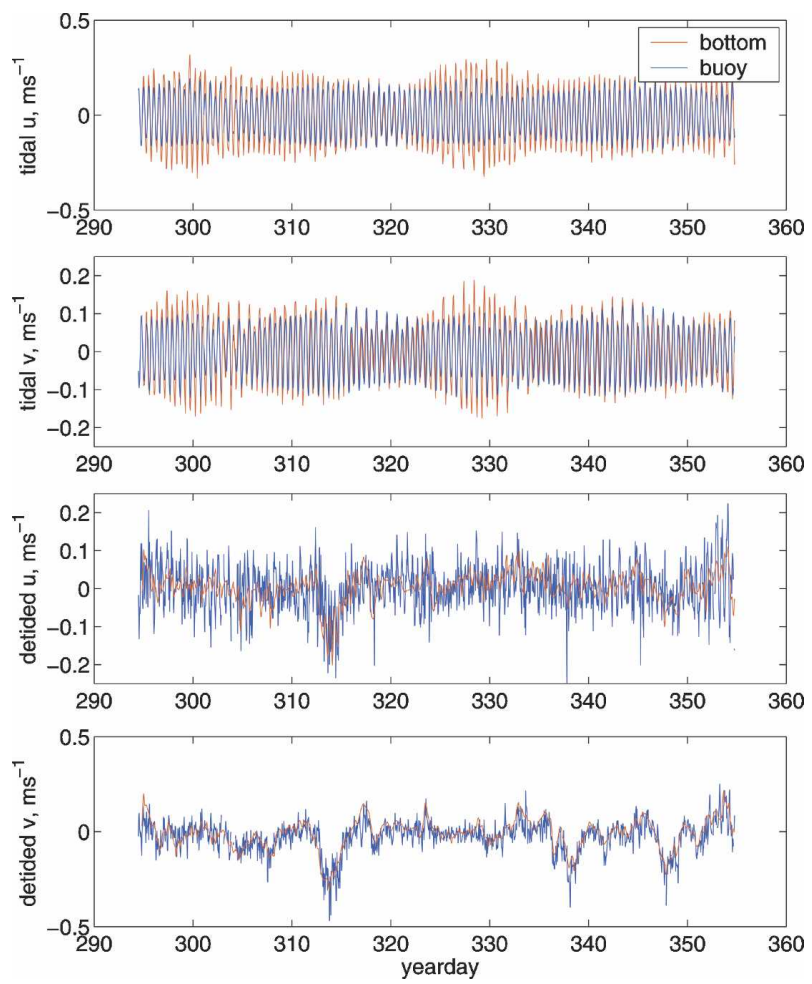

FIG. 10. (top two) Tidal fit to the $u$ and $v$ components of velocity, and (bottom two) the detided velocities from the bottom- and buoy-mounted instruments at $10.5-\mathrm{m}$ depth. All velocities are in meters per second.

possibly input of energy at the surface in the same frequency band. The greater $M_{3}$ and $M_{6}$ tide in $u$ and greater $M_{4}$ tide in $v$ suggests rather different overtide generation mechanisms operating in the across- and alongshore directions. We leave further investigation of these topics to a later time.

An overlay of spectra of midwater column velocities (Fig. 11) suggests that buoy-mounted measurements provide a reasonable measure of energy content for $f<$ $0.1 \mathrm{cph}$, but are dominated by noise at higher frequencies. We therefore examine the low-pass- and highpass-filtered records below to more fully understand the distinction.

\section{d. Low-pass data}

To examine low-frequency variability, buoy- and bottom-mounted ADCP velocities in each bin are filtered with a 40-h fourth-order low-pass Butterworth filter. The filtered bottom-mounted ADCP time series are then interpolated to the buoy sampling in time and space for direct comparison as discussed above.

Forty-hour low-pass-filtered records from the three depths sampled reveal the character of the wind-driven
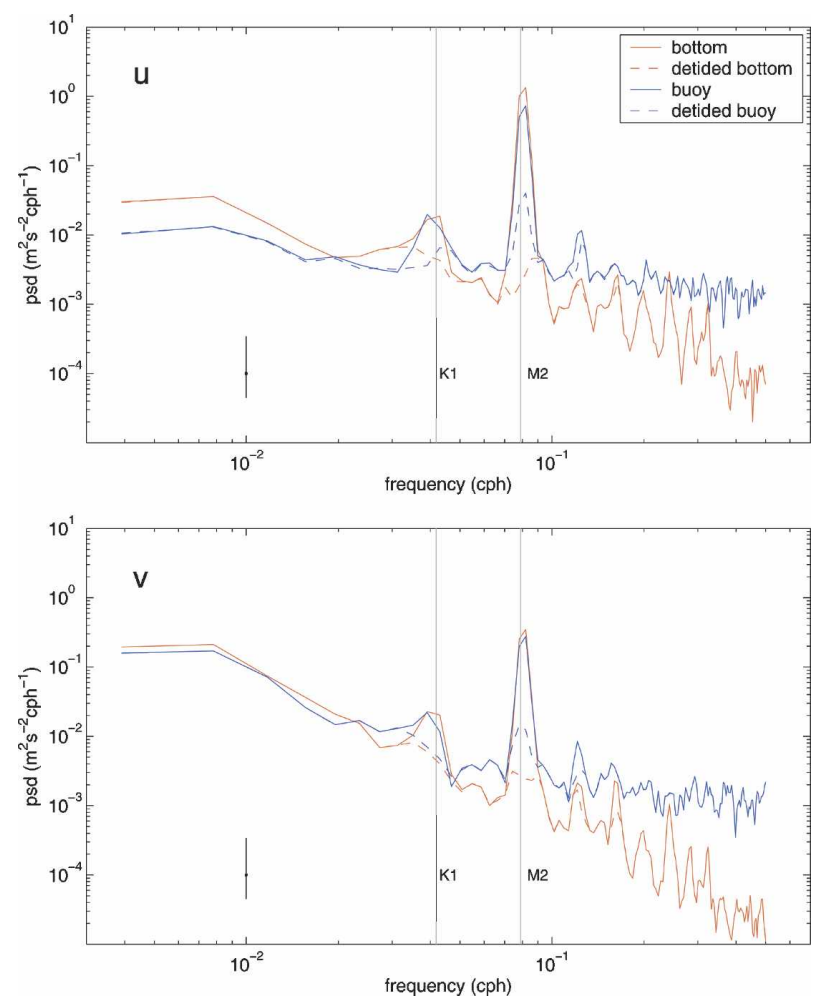

FIG. 11. Power spectral density estimates $\left(\mathrm{m}^{2} \mathrm{~s}^{-2} \mathrm{cph}^{-1}\right)$ of the total (solid) and detided (dashed) time series at 10.5-m depth. Bottom-based (red) and buoy-mounted (blue) spectra are shown for the (top) $u$ and (bottom) $v$ components of velocity. The black vertical lines denote the $95 \%$ confidence interval for the spectral estimates.

flow (Fig. 13). Currents are strongest in the along-shelf direction, which is approximately meridional. Offshore flow is greatest near the surface and is associated with considerable vertical shear in the zonal currents; onshore flow is more uniform with depth. This asymmetric flow response to alongshore winds reflects the mean exchange flow in the CFZ (Blanton 1996). Though a relatively large event on 10 November (yearday 314) drove a westward current greater than $0.1 \mathrm{~m} \mathrm{~s}^{-1}$, this largely cross-shore velocity component is typically $<0.05 \mathrm{~m} \mathrm{~s}^{-1}$. Correlation coefficients of the $u$ and $v$ components measured by the two ADCPS are 0.49 and 0.64 , respectively, while RMS differences are roughly comparable $\left(0.022\right.$ and $0.025 \mathrm{~m} \mathrm{~s}^{-1}$ for the east-west and north-south directions). Time series of nearbottom filtered velocities are shown in Fig. 14, and further illustrate the magnitude and variability of the velocity differences between the instruments. We note a bias in the meridional velocity, where the buoymounted ADCP fails to capture most of the stronger northward flows and tends to overestimate southward currents. The magnitude of this bias corresponds well 


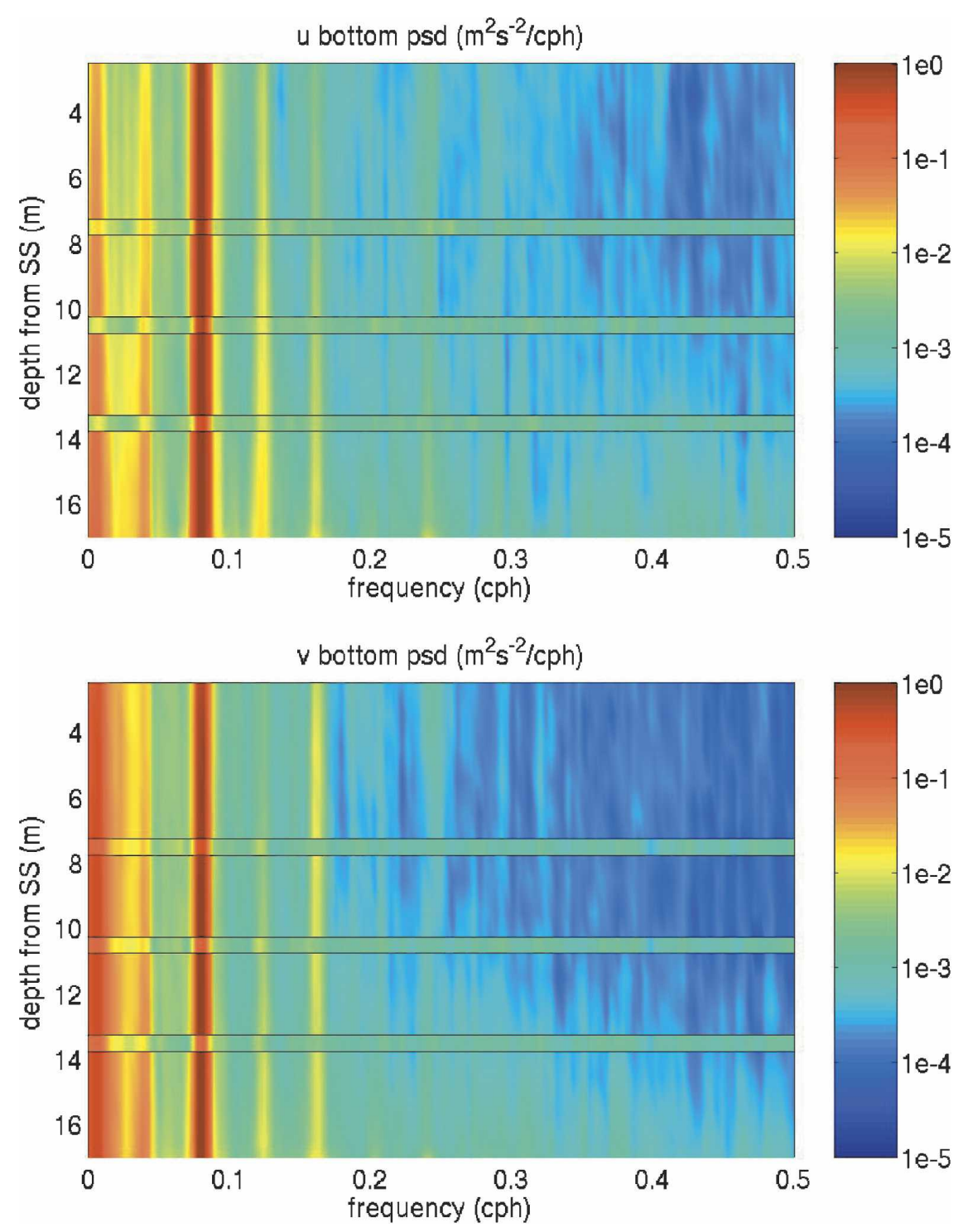

FIG. 12. Power spectral density $\left(\mathrm{m}^{2} \mathrm{~s}^{-2} \mathrm{cph}^{-1}\right)$ of the $u$ and $v$ components of velocity measured by the bottom- (background) and buoy-mounted (overlaid strips) ADCPs.

with that found in the regression of unfiltered velocities $\left(\sim 0.02 \mathrm{~m} \mathrm{~s}^{-1}\right)$, but the cause of this bias is unclear.

We interpret the poor performance of the buoymounted system to be related to its large noise floor and small current speeds. Given the importance of lowfrequency flow in determining net transport on the shelf, this poses a significant challenge for instrumentation.

\section{e. High-pass data}

High-pass-filtered data are examined using a 10thorder 10-h Butterworth filter, which excludes the diurnal and semidiurnal tides. The order of the filter is increased for the higher-frequency cutoff to more completely reject the semidiurnal tide, reducing the power in the tidal band by more than two decades $(<1 \%)$ below that of the original signal.

The 10-h high-pass data show a marked difference in the high-frequency content of the buoy- and bottommounted observations (Fig. 15). Figure 15 shows bursts of vertically coherent signal occurring at irregular intervals and strength on the order of $0.05 \mathrm{~m} \mathrm{~s}^{-1}$; the high-passed currents measured by the bottom-mounted instrument (red) are notably less energetic, exhibiting maxima at spring tides, likely a signature of overtides.

The "events" evident in the buoy-mounted record 

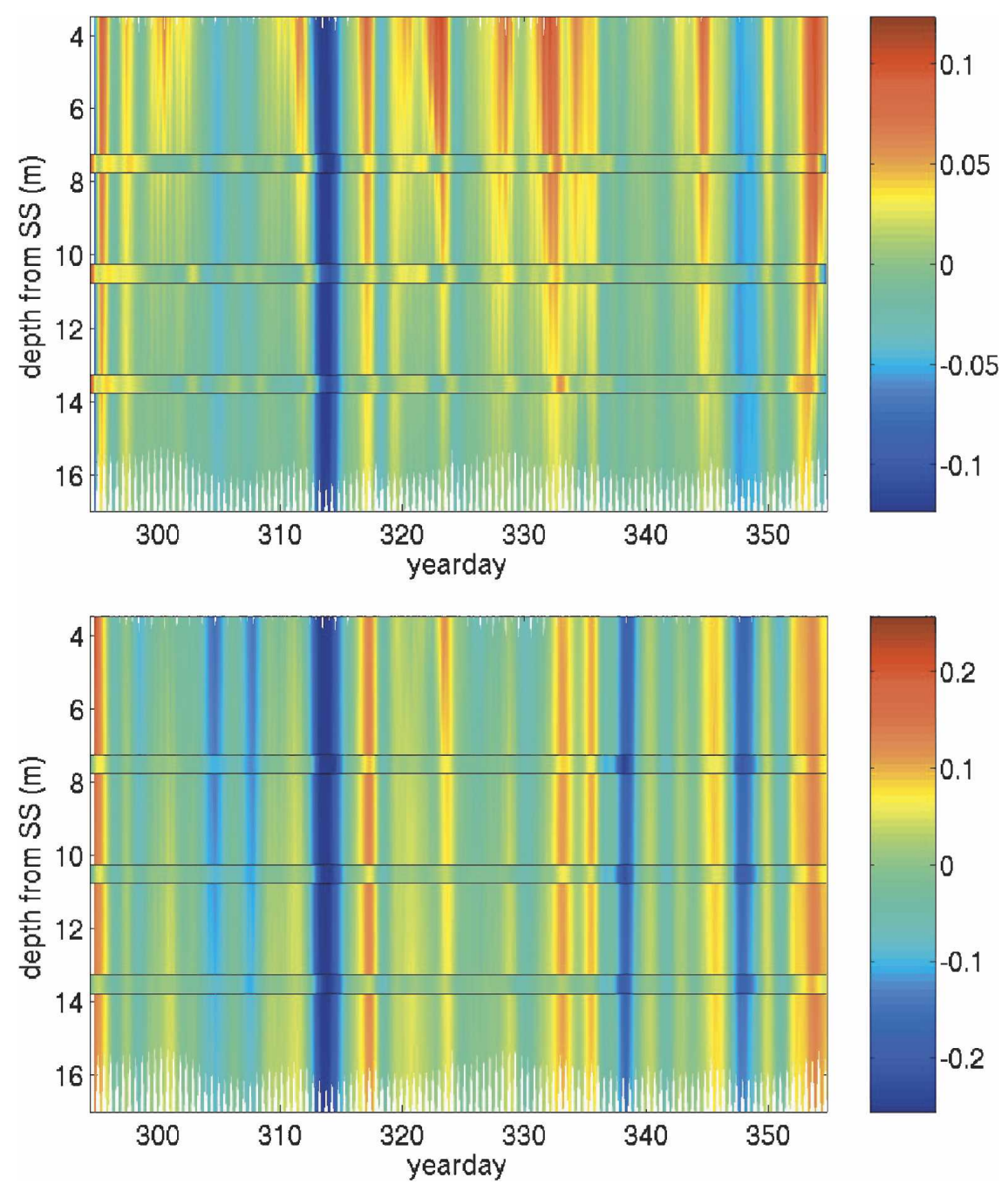

FIG. 13. The 40-h low-pass-filtered (top) zonal and (bottom) meridional velocities from the bottom- (background) and buoy-mounted (overlaid strips) ADCPs. Time is shown in yeardays, velocities are in meters per second, and depth is in meters below sea surface.

correlate with periods of increased surface wave activity and are likely due to buoy/mooring motion. The episodic nature of the increased high-frequency current variance is shown in Fig. 16, with a measure of highfrequency wave activity - the spectral wave density, collected by the NDBC buoy, taken as a sum over frequencies from 0.0325 to $0.485 \mathrm{~Hz}$. The temporal coherence of spectral wave density and near-surface highfrequency currents, particularly the highest energy wave events near yeardays 314 and 337, suggests that wave motion is the source of supertidal noise evident in the buoy-mounted data. The visual coherence of the bursts of high-frequency velocities and the surface wave activity imply significant contamination of the averaged velocity by the wave field.

\section{Discussion}

Tidal, spectral, and filtering analyses used to compare buoy- and bottom-mounted ADCP performance at Gray's Reef indicate a number of potential problems that affect the quality of buoy-mounted measured velocities. Some of the issues identified here can be and have been addressed easily; others warrant further discussion and more complete analysis.

Vertical binning of the buoy-mounted ADCP is relatively coarse given the shallow $(18 \mathrm{~m})$ depth at the buoy site. In the configuration used, the center of the first vertical bin was $7.5 \mathrm{~m}$ below the sea surface, $2.5 \mathrm{~m}$ of which is due to the position of the cage in the mooring chain. Use of a higher-frequency instrument would de- 

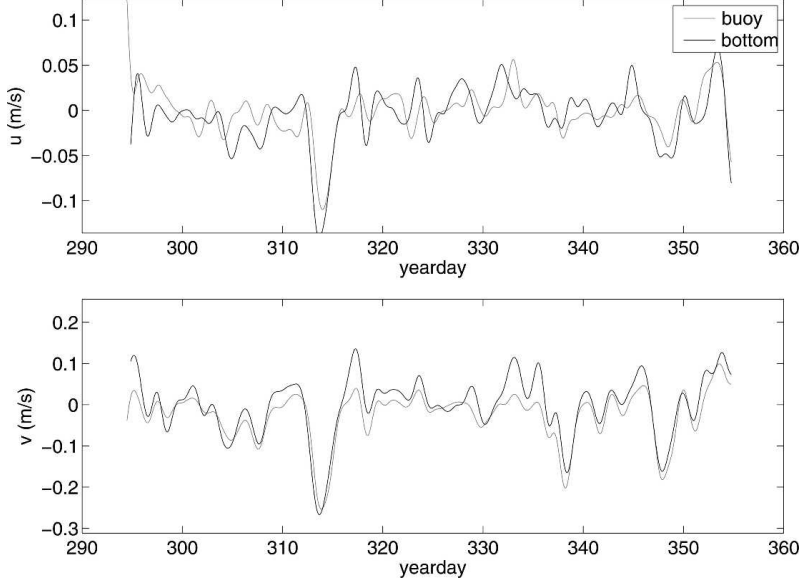

FIG. 14. Time series of 40-h low-pass-filtered (top) zonal and (bottom) meridional velocities at $13.5 \mathrm{~m}$ below the sea surface as measured by the buoy-mounted (gray) and the bottom-mounted (black) ADCPs. Velocities are shown in meters per second. The bottom-mounted and buoy-mounted ADCPs record $(-6.2,0.3)$ and $(-0.9,-25.5) \mathrm{mm} \mathrm{s}^{-1}$ mean $(u, v)$ flow, respectively, at this depth level.

crease the distance from the transducer to the center of the first bin, allow for increased vertical resolution, and lower the ensemble standard deviation. However, even a $1200-\mathrm{kHz}$ instrument would still only measure the bottom two-thirds of the water column given the shallow depth and the mooring configuration. The combination of increasing instrument frequency and decreasing the depth of the ADCP with respect to the sea surface would allow for a more complete measurement of the water column.

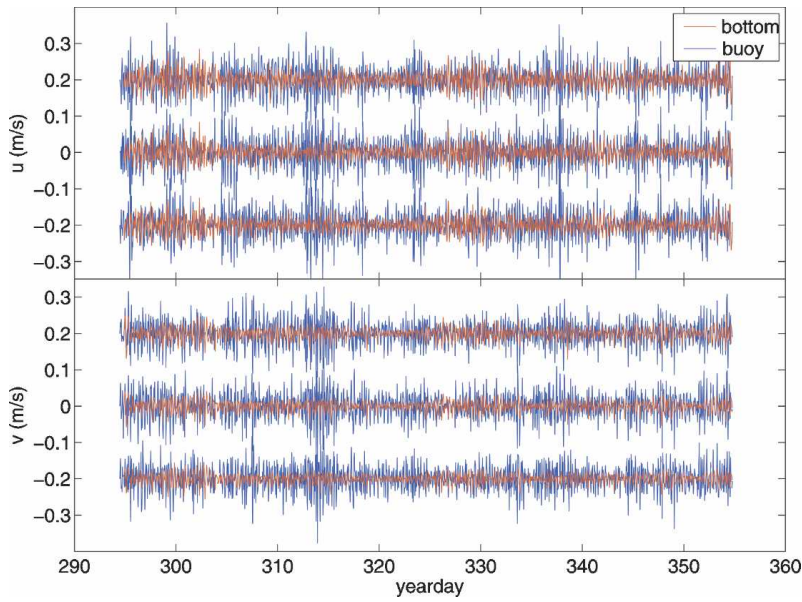

FIG. 15. 60-day time series of 10-h high-pass-filtered $u$ and $v$ components of velocity at (top) 7.5, (middle) 10.5, and (bottom) $13.5 \mathrm{~m}$ below the sea surface as measured by the bottom- (red) and buoy-mounted (blue) ADCPs. Each velocity bin is offset by $0.2 \mathrm{~m} \mathrm{~s}^{-1}$ for clarity.

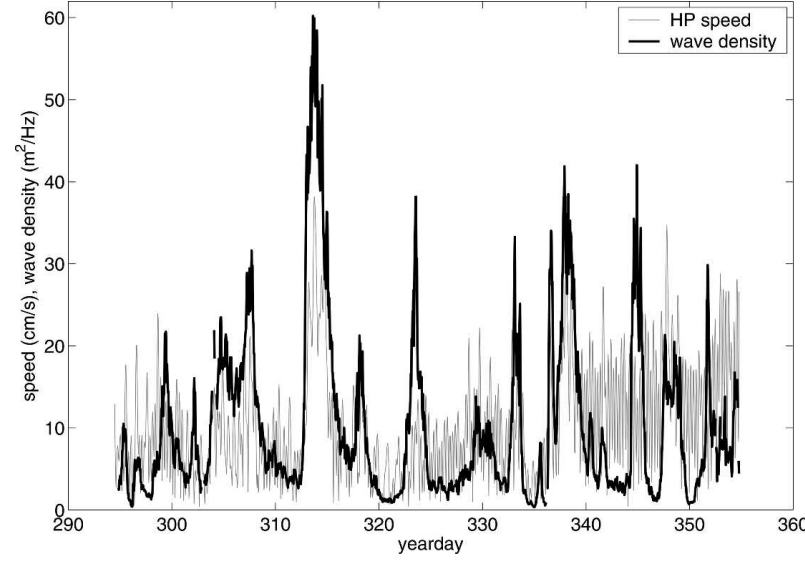

FIG. 16. 60-day time series of 10-h high-pass-filtered speeds at $13.5 \mathrm{~m}$ below the sea surface as measured by the buoy-mounted ADCP (gray). Total spectral wave density is shown in black.

The sampling rate used on the buoy-mounted ADCP (1 ping every half-minute, with 120 pings averaged to produce hourly averages) was not optimal. Given that the surface waves are most energetic at $5-10$-s periods, this sampling scheme provides an aliased measure of currents associated with surface waves and the mooring motions induced by the waves. It would be preferable to sample at a rate that resolves the wave field. [We note that in the reconfigured deployment now at Gray's Reef National Marine Sanctuary (GRNMS) burst sampling is used, with 1-s pings collected for 6 min to form an ensemble each hour.] It is hoped that this will allow the high-frequency motions to be "averaged out." We note, however, that the bottom-mounted ADCP, which (resulting from a configuration error) used a sampling rate of one ping every $9 \mathrm{~s}$, did not display an elevated velocity noise floor. This suggests that aliased measurement of the wave field alone cannot explain the elevated noise floor.

It is suggested that surface waves produce noise at supertidal frequencies in the horizontal velocities of the buoy-mounted system because of an inability to correctly account for mooring motion. Existing pitch-androll corrections are not working, as evidenced by the large vertical velocities, and may be exacerbating velocity differences resulting from the wave field. There are several options to address this problem. The simplest solution would be to turn off pitch-and-roll corrections with continued use of the existing in-line cage, and hope that errors "average out." The relatively large mean tilts seen in Fig. 5 suggest that this is not an ideal solution. Alternatively, the ADCP could be moved into a bridle mount, which should reduce mean tilts and improve vertical coverage by moving the ADCP closer to the surface. Pitch-and-roll variance will likely in- 
crease, however, and may make the noise level rise. The revised configuration would make possible the use of external onboard pitch-and-roll sensors with better dynamic response (e.g., those used by NDBC to sense the wave field) to accurately account for buoy motion in rough seas. This will present a challenging, but not insurmountable, interface problem.

An examination of the tidal signals shows general disagreement of the amplitudes, phases, and eccentricities of measurable tidal constituents. The magnitude of the underestimate of the tide by the buoy-mounted ADCP is due, in part, to the transfer of the signal into the vertical by the pitch-and-roll correction, but the correction does not fully explain the underestimate (cf. Fig. 6). First, there is no significant change in the wave field when observational quality of the buoy-mounted ADCP improves (e.g., Fig. 3). Second, the underestimate of tidal amplitudes varies with depth, being more severe near the seafloor, and therefore cannot be explained by pitch-and-roll issues alone.

We postulate that at least part of the underestimate results from obstruction of the acoustic beam by an object with near-zero velocity. The scenario envisioned is that over part of the sampling period of an hour, the near-zero velocity scatterers dominate the return. These single-ping near-zero velocity estimates bias the ensemble velocity toward zero when included in the hour averages. The two likely candidates for producing this interference are either the mooring chain or fish/ plankton. Very similar current reductions associated with enhanced backscatter were observed by Moore and Stewart (2003) on a deep-water mooring that they ascribed to mobile scatterers. It is obvious from the tilts seen in the buoy-mounted system that a significant catenary exists in the mooring chain (recall that the buoymounted ADCP is held in a cage that forms part of the mooring and is not rigidly attached to the buoy). If the tilt is $10^{\circ}$ at the base of the buoy during strong storms, the chain may be fully extended, leading to large angles in the chain near the bottom. This increases the likelihood that the mooring chain will be in the water ensonified by an ADCP beam. If the strong scattering from the chain is not rejected, it should be a near-zero velocity estimate, which when averaged into the hourlong ensembles will bias average velocities toward zero, as observed.

The other possibility is that fish aggregations or plankton migrations may be causing the enhanced backscatter and velocity underestimates. Significant numbers of fish were observed aggregating around the buoy during the deployment of the bottom-mounted ADCP frame (P. Work 2003, personal communication). The ADCP manufacturer [RD Instruments (RDI)] implements an algorithm to anomalously reject largeecho intensities (called false targets), but this is based on a simple thresholding. The threshold was set to a reasonable value of 50. More sophisticated postprocessing of single-ping data to reduce the possible fish bias has been developed (e.g., Plimpton et al. 1997), but it is not feasible for a real-time system. Rejection of threebeam ADCP solutions may help reduce any effect from either source of interference. We cannot definitively identify the cause of interference with only ensembleaveraged observations but note that both tidal and diel variations are obvious in the basckscatter signal, suggesting both are active. Analysis of the unaveraged single-ping data would improve understanding of potential interference.

Low-frequency flow is poorly represented by the buoy-mounted system except when speeds exceed 0.05 $\mathrm{m} \mathrm{s}^{-1}$, consistent with the noise floor resulting from surface wave contamination. There appears to be a slight bias in the north-south velocities (greater mean southward flow seen in the buoy-mounted observations), which may be an indication of the dominant wave direction (Lohrmann 1998) or possibly due to a small $\left(<5^{\circ}\right)$ alignment error. However, the large existing uncertainties make the cause of the small bias unclear.

The comparisons here suggest that similar analysis be performed for the other ADCP-instrumented buoy sites. The two southern California buoys (46023 and 46054, near Point Arguello and Santa Barbara, respectively) are at $10 \mathrm{~m}$ and likely do not suffer to the same degree that the smaller shallow-water buoy systems do, such as that at Gray's Reef, though Winant et al. (1994) report that large surface waves adversely impact buoymounted ADCP observational quality. Visual inspection of recent data collected by the NDBC buoy near St. Augustine, Florida (buoy 41012), suggests possible bottom interference, and its location on the shallow shelf may yield sufficient wave activity to similarly contaminate the measured velocities with high-frequency noise.

There is obviously a need to better understand the mooring dynamics in shallow-water environments. Reasonably sophisticated models exist (e.g., Dewey 1999), but require careful specification of mooring component attributes, especially the surface buoy. We hope to pursue this type of modeling in the near future.

We also note that the Gray's Reef buoy and mooring has already been reconfigured based on preliminary analysis conducted as part of this study. A $600-\mathrm{kHz}$ RDI Workhorse unit using 1-m vertical bins and burst sampling 300 one-second pings for 5 min each hour has 
been deployed since fall of 2005. A second intercomparison study will be conducted in early 2006 to assess how these simple changes affect data quality.

\section{Conclusions}

An intercomparison of 2 months of ADCP current measurements from an NDBC buoy- and a bottommounted instrument deployment in a shallow $(<20 \mathrm{~m}$ deep) shelf environment is conducted using 2 months of observations from late 2003. The buoy-mounted measurements employ a $300-\mathrm{kHz}$ system and provide limited vertical coverage. Overall variance is underestimated by the buoy-mounted system, due largely to an underestimate of the tidal currents that dominate kinetic energy on the shelf. Power spectra differ markedly; the buoy-mounted spectra are essentially white whereas the spectra from bottom-mounted system are red. Minimum spectral levels imply an effective noise floor of the buoy-mounted system of $0.045 \mathrm{~m} \mathrm{~s}^{-1}$. The correlation of high-frequency velocities and wave energy levels suggest wave-induced buoy motions produce the observed "noise."

The weak mean subtidal flows characteristic of the shelf are poorly represented in the buoy-mounted observations because of the large noise floor, and are a challenge to observe accurately. A persistent underestimate of tidal currents and subtidal flows is observed and is postulated to be caused by interference in the water column. The interference is thought to be caused by the mooring chain and/or fish/plankton that introduce near-zero velocities into ensemble averages and bias current estimates toward zero.

Acknowledgments. We thank the crew of the Research Vessel (R/V) Savannah, Paul Work, and Trent Moore for deploying and recovering the bottommounted ADCP. Cathy Woody at NDBC played an important role in fostering our interaction, as did Richard Bouchard and Richard Crout. We also thank two anonymous reviewers for their thoughtful comments, which significantly improved the manuscript. This work was supported as part of SEACOOS, sponsored by the Office of Naval Research under Award N00014-02-10972.

\section{REFERENCES}

Appell, G. F., and R. G. Williams, 1993: Laboratory and field measurements with a broad band ADCP. IEEE J. Oceanic Eng., 16, 390-393.

Blanton, B., and Coauthors, 2004: Barotropic tides in the South Atlantic Bight. J. Geophys. Res., 109, C12024, doi:10.1029/ 2004JC002455.
Blanton, J. O., 1981: Ocean currents along a nearshore frontal zone on the continental shelf of the southeastern United States. J. Phys. Oceanogr., 11, 1627-1637.

_ 1996: Reinforcement of gravitational circulation by wind. Buoyancy Effect on Coastal and Estuarine Dynamics, D. G. Aubrey and C. T. Friedrichs, Ed., Coastal and Estuarine Studies, Vol. 53, Amer. Geophys. Union, 47-58.

Bosley, K. T., J. Dussault, C. McGrath, and J. Stepnowski, 2005: Real-time current measurements on U.S. Coast Guard navigation buoys. Proceedings of the IEEE/OES Eighth Working Conference on Current Measurement Technology, J. Rizoli White and S. Anderson, Eds., IEEE/OES, 122-126.

Commission on Ocean Policy, 2004: An ocean blueprint for the 21st century. Final Report of the U.S. Commission on Ocean Policy, Washington, DC, 676 pp. [Available online at http://www.oceancommission.gov/documents/prepub_ report/welcome.html.]

Dewey, R. K., 1999: Mooring Design \& Dynamics-A Matlab package for designing and analyzing oceanographic moorings. Mar. Model., 1, 103-157.

Frosch, R., 2000: An integrated ocean observing system: A strategy for implementing the first steps of U.S. plan. Ocean Observations Task Team, ORAP Rep. to NORLC, 39 pp. [Available online at http://www.coreocean.org/Dev2Go. web?id=220672.]

Gargett, A., J. Wells, A. E. Tejada-Martinez, and C. E. Grosch, 2004: Langmuir supercells: A mechanism for sediment resuspension and transport in shallow seas. Science, 306, 19251928.

Lee, T. N., J. A. Yoder, and L. P. Atkinson, 1991: Gulf Stream frontal eddy influence on productivity of the Southeast U.S. continental shelf. J. Geophys. Res., 96, 22 191-22 205.

Lohrmann, A., 1998: Comparison of buoy mounted NDP current velocity data with upward looking ADCP data. Nortek Tech. Note 001, 4 pp.

Moore, A. N., and D. S. Stewart, 2003: The effects of mobile scatterers on the quality of ADCP data in differing marine environments. Proc. IEEE/OES Seventh Working Conf. on Current Measurement Technology, San Diego, CA, IEEE/ OES, 202-206.

OCEAN.US, cited 2002: An integrated and sustained ocean observing system (IOOS) for the United States: Design and implementation. OCEAN.US Rep., Arlington, VA, 21 pp. [Available online at http://www.ocean.us/documents/docs/ FINAL-ImpPlan-NORLC.pdf.]

Pawlowicz, R., B. Beardsley, and S. Lentz, 2002: Classical tidal harmonic analysis including error estimates in MATLAB using T_TIDE. Comput. Geosci., 28, 929-937.

Pietrafesa, L. J., J. O. Blanton, J. D. Wang, V. Kourafalou, T. N. Lee, and K. A. Bush, 1985: The tidal regime in the South Atlantic Bight. Oceanography of the Southeastern U.S. Continental Shelf, L. P. Atkinson, D. W. Menzel, and K. A. Bush, Eds., Coastal and Estuarine Sciences Series, Vol. 2, Amer. Geophys. Union, 63-76.

Plimpton, P. E., H. P. Freitag, and M. J. McPhaden, 1997: ADCP velocity errors from pelagic fish schooling around equatorial moorings. J. Atmos. Oceanic Technol., 14, 1212-1223.

Winant, C., T. Mettlach, and S. Larson, 1994: Comparison of buoy-mounted $75-\mathrm{kHz}$ acoustic Doppler current profilers with vector-measuring current meters. J. Atmos. Oceanic Technol., 11, 1317-1333. 
Copyright of Journal of Atmospheric \& Oceanic Technology is the property of American Meteorological Society and its content may not be copied or emailed to multiple sites or posted to a listserv without the copyright holder's express written permission. However, users may print. download, or email articles for individual use. 